\title{
Neurological Manifestations of Maxillofacial Trauma
}

\author{
Sara Taha ${ }^{1}$ and Yousif I Eltohami ${ }^{2 *}$ \\ ${ }^{1}$ Dental Student, University of Khartoum, Sudan \\ ${ }^{2}$ Department of Oral and Maxillofacial Surgery, University of Khartoum, Sudan
}

Submission: June 23, 2018; Published: July 16, 2018

*Corresponding author: Yousif I Eltohami, Assistant professor of Oral and Maxillofacial Surgery, Faculty of Dentistry, University of Khartoum, Sudan, Email: Yof88@hotmail.com

Abstract

Objectives: The current study aimed to determine the frequency of neurological manifestations associated with maxillofacial trauma, such as loss of consciousness, post-traumatic amnesia and other symptoms of closed-head injury.

Methodology: A retrospective chart review of 75 patients with maxillofacial trauma was conducted. Data was collected on the cause and site of trauma, GCS score, loss of consciousness, post-traumatic amnesia and other symptoms of closed-head injury.

Results: Loss of consciousness was reported in $38.7 \%$ of patients, the duration of loss of consciousness ranged from less than 30 minutes to over 6 hours. Anterograde amnesia was found in 1.3\% of patients. Retrograde amnesia was reported in $18.7 \%$ of patients. The duration of retrograde amnesia ranged from 15 minutes to several days, with a mean duration of 15 hours. Headache was reported in $18.7 \%$ of patients, dizziness was reported in $14.7 \%$ of patients, blurred vision was reported in $8 \%$ of patients and nausea and vomiting was experienced by $2.7 \%$ of patients following injury.

Conclusion: Neurological manifestations are commonly associated with maxillofacial trauma and it is necessary to investigate their presence in patients presenting with maxillofacial trauma in order to initiate proper management and to avoid further complications.

Keywords: Trauma; Maxillofacial region; Amnesia; Loss of consciouness

\section{Introduction}

Trauma poses a great threat to global public health as it is one of the leading causes of morbidity and mortality worldwide.

Because of its prominent position in the body, the maxillofacial region is one that is particularly prone to injury, rendering it a common presentation in emergency rooms and a significant contributor to the global burden of this disease $[1,2]$.

Maxillofacial trauma can occur as an isolated injury or in combination with other injuries such as injuries to the head, which carry a significant potential for mortality and neurological morbidity, as even some of the mildest types of brain injury have been shown to have persistent, and sometimes progressive, long-term debilitating effects.

Despite the little amount of literature available regarding the association between maxillofacial trauma and accompanying head injuries, studies have shown that there is a high incidence of traumatic brain injury accompanying maxillofacial trauma due to the impact of forces transmitted through the head and neck.

Traumatic brain injury, also known as intracranial injury, is defined as an alteration in brain function, or other evidence of brain pathology, caused by an external force (such as rapid acceleration/deceleration or impact). Commonly caused by falls, road traffic accidents and assault, it is the most common cause of death and disability in young people and is predicted to surpass many diseases as the major cause of death and disability by the year 2020 [3]. The burden of this disease is significantly greater in low- and middle-income countries such as Sudan in which there is higher risk for it and where health systems are inadequately prepared to address the associated health outcomes [1].

Depending on the severity of the injury, patients with brain injuries due to trauma may experience a varying array of symptoms. Brain injuries can be classified into mild, moderate, and severe categories. The Glasgow Coma Scale (GCS), the most commonly used system for classifying TBI severity, grades a person's level of consciousness on a scale of 3-15 based on verbal, motor, and eye-opening reactions to stimuli.

A GCS score of 13 or higher generally correlates with a mild brain injury, 9 to 12 is a moderate injury and 8 or less a severe brain injury. Around $80 \%$ of all TBI cases are categorized as mild head injuries $[4,5]$. However, many of the patients suffering mild brain injuries are oriented by the time they are first assessed 
and therefore score at the top of the Glasgow scale, which only recognizes patients with MTBI as those with a GCS score of 13-15. Yet some of these patients have had a period of altered consciousness, either witnessed or evidenced by their being amnesic for events immediately following injury. This poses a problem in developing countries, where the Glasgow Coma Scale is highly relied on in assessing the severity of brain injury, and as a result, patients with milder forms of brain injury are oftentimes left undiagnosed.

To solve this problem, the duration of post-traumatic amnesia was then taken into account as it makes up for the insensitivity of the Glasgow Coma Scale in diagnosing patients suffering milder forms of brain injury. Nowadays, healthcare providers rank the patient's level of consciousness, post-traumatic amnesia (retrograde and anterograde amnesia), and GCS score in order to measure the severity of their brain injury.

The aim of this research is to determine the frequency of neurological manifestations associated with maxillofacial trauma, such as loss of consciousness, post-traumatic amnesia and other symptoms of closed-head injury.

\section{Methodology}

Ethical approval to carry out this study was obtained from University of Khartoum, Faculty of Dentistry's Ethical Committee Review Board, and from the research unit at Khartoum Teaching Dental Hospital. This study utilized a retrospective cross-sectional study design and was carried out in Khartoum Teaching Dental Hospital, which is the main center of Oral and Maxillofacial surgery in Sudan. The aim of this study was to determine the frequency of loss of consciousness, post- traumatic amnesia, and other symptoms of closed-head injury among patients presenting to the hospital with maxillofacial fractures.

Total coverage of all patients records from 2015 to 2018 that fulfilled inclusion and exclusion criteria were included. Accordingly, the sample size was 75 patients, and the age of the patients ranged between 18 and 70 years.

Data was collected from completed records of patients using a data collection sheet. The completed data collection sheet contained the following information:
a) Age
b) Gender
c) Cause of injury
d) Site of injury
e) GCS score
f) Loss of consciousness and duration (if present)
g) Post-traumatic amnesia and duration (if present)
h) Presence of other symptoms of closed-head injury

Data was collected and entered to the Statistical Package for Social Sciences (SPSS) program (version 20) in the computer. Graphs were used to represent the results.

\section{Results}

a) The study included a total of 75 patients, $68(90.7 \%)$ of whom were males and 7 (9.3\%) were females (Figure 1).

\section{Gender}

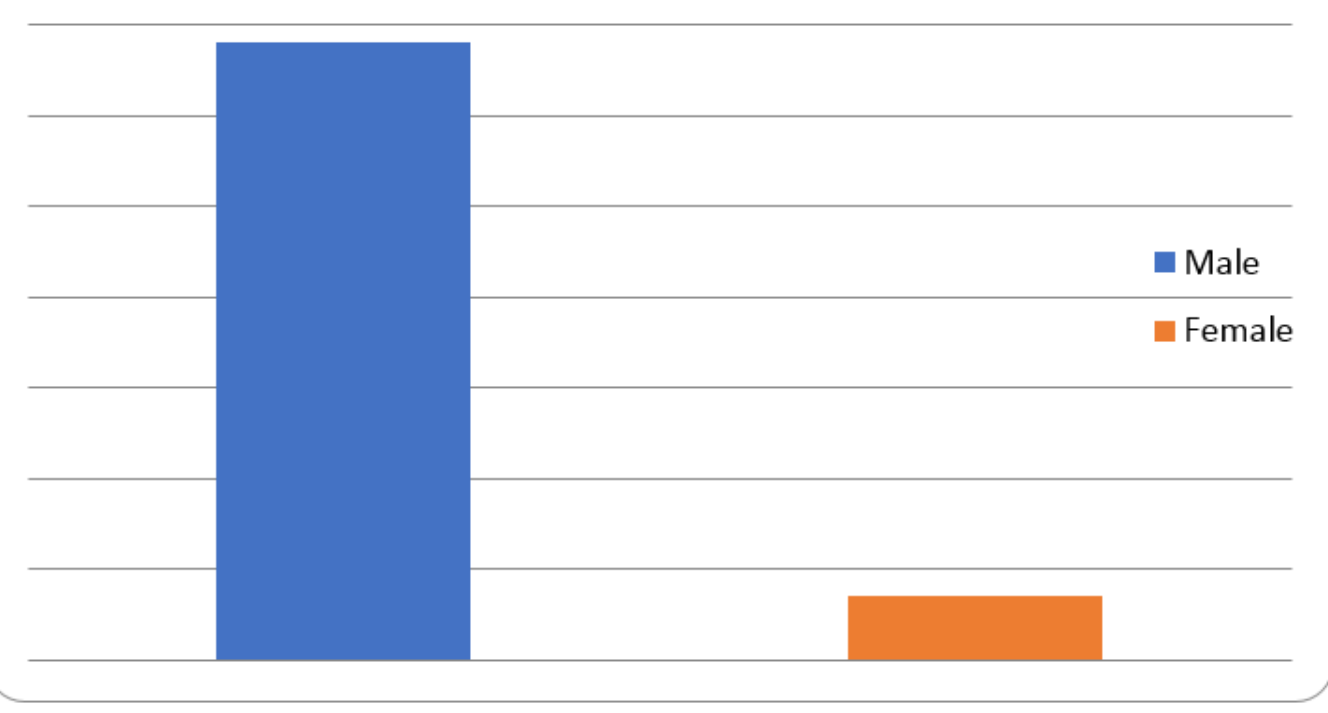

Figure 1: Shows Gender distribution of Maxillofacial Trauma patients. 
b) Regarding the age distribution the youngest patient included in the study was of 18 years and the eldest was 70 . The mean age was 33 years (Figure 2).

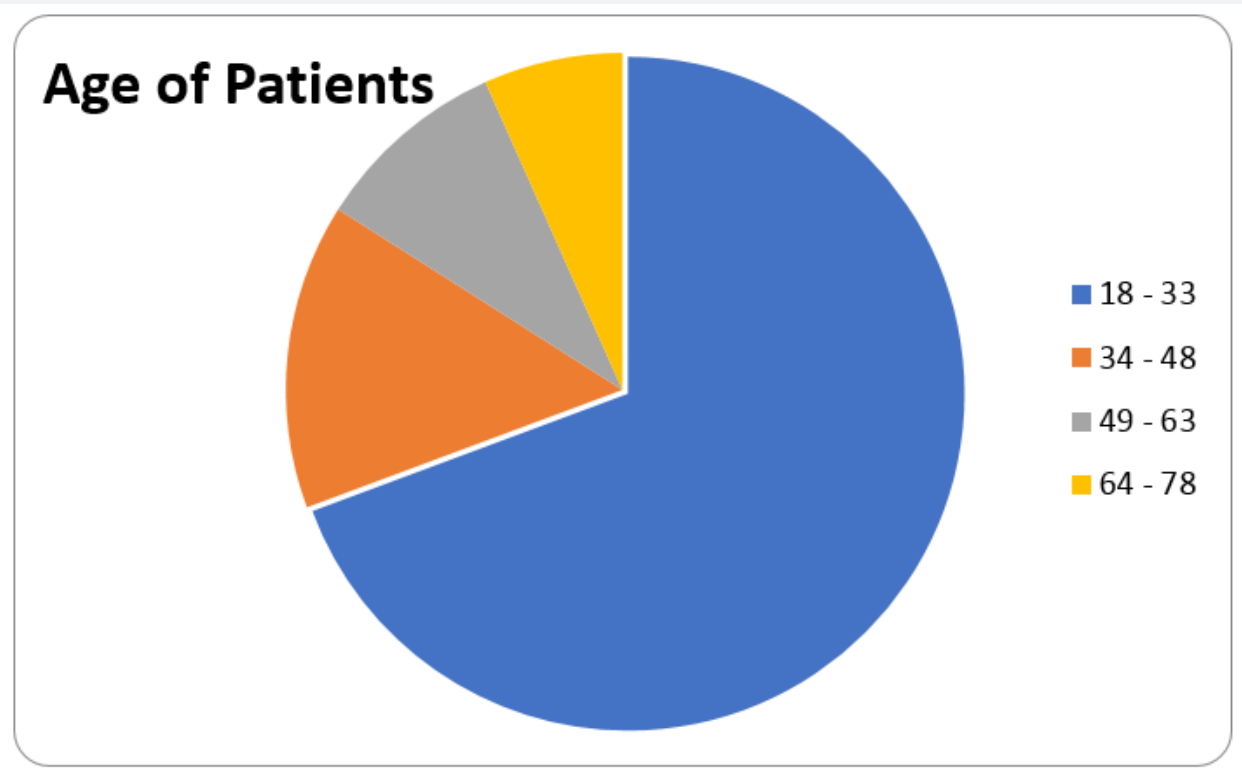

Figure 2: Shows Age distribution of Maxillofacial Trauma patients.

c) Regarding the causes of injury, RTA's were the most common cause, accounting for 35 injuries (47\%), followed by assault causing 22 injuries (29\%), followed by falls causing 12 injuries (16\%), followed by sport-related injuries, causing 3 injuries (4\%) and 3 Other injuries accounting for (4\%). The injuries in the "Other" category was 1 blast injury, 1 traumatic extraction and 1 work-related injury (Figure 3).

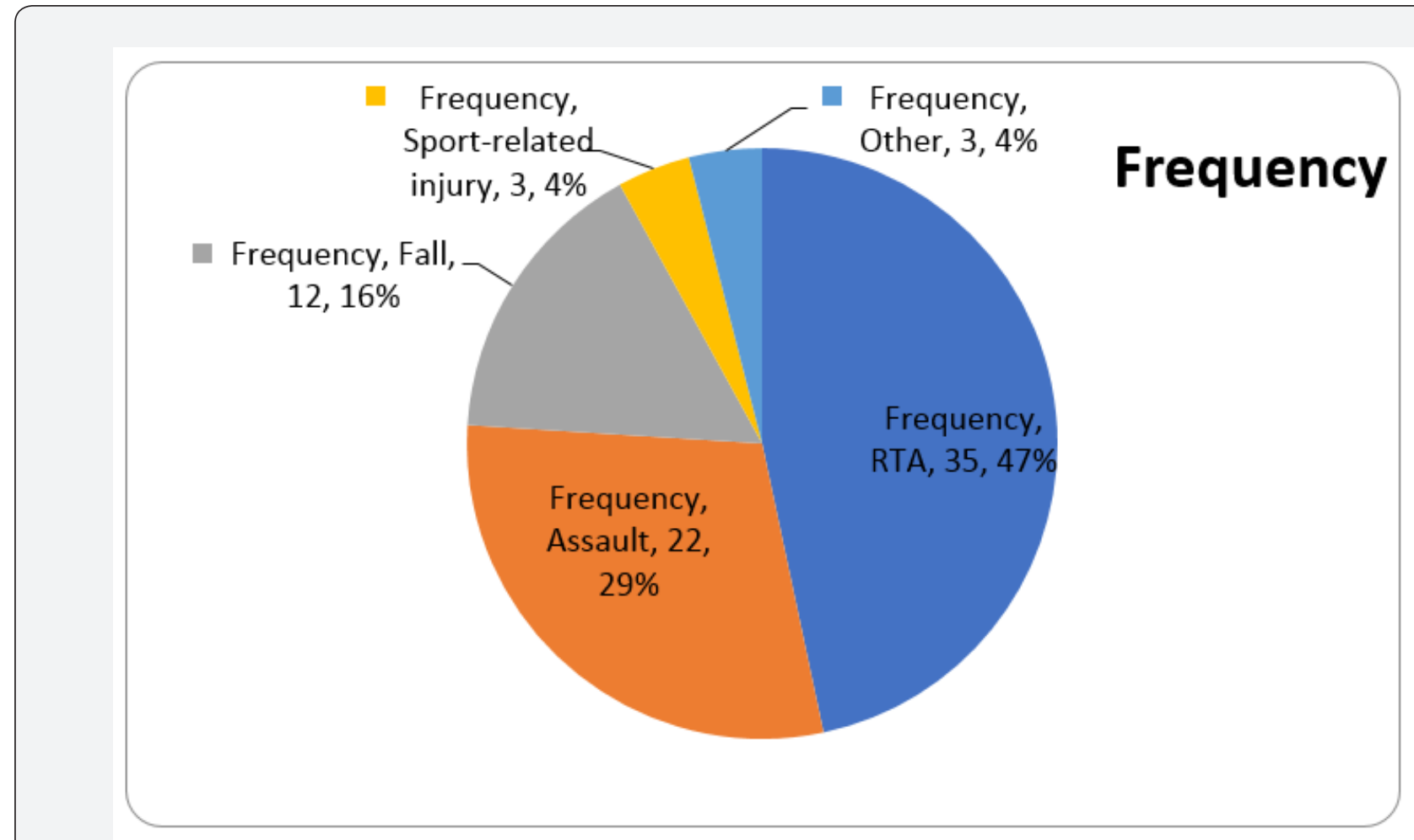

Figure 3: Shows Causes of Injury. 
d) Concerning the types of injuries, the most common type of injury was fracture of the parasymphesis $(20.7 \%)$, followed by the body of the mandible (19.8\%) and the zygomatic complex (18\%) while the least encountered fractures were those of the upper third of the face (Figure 4).

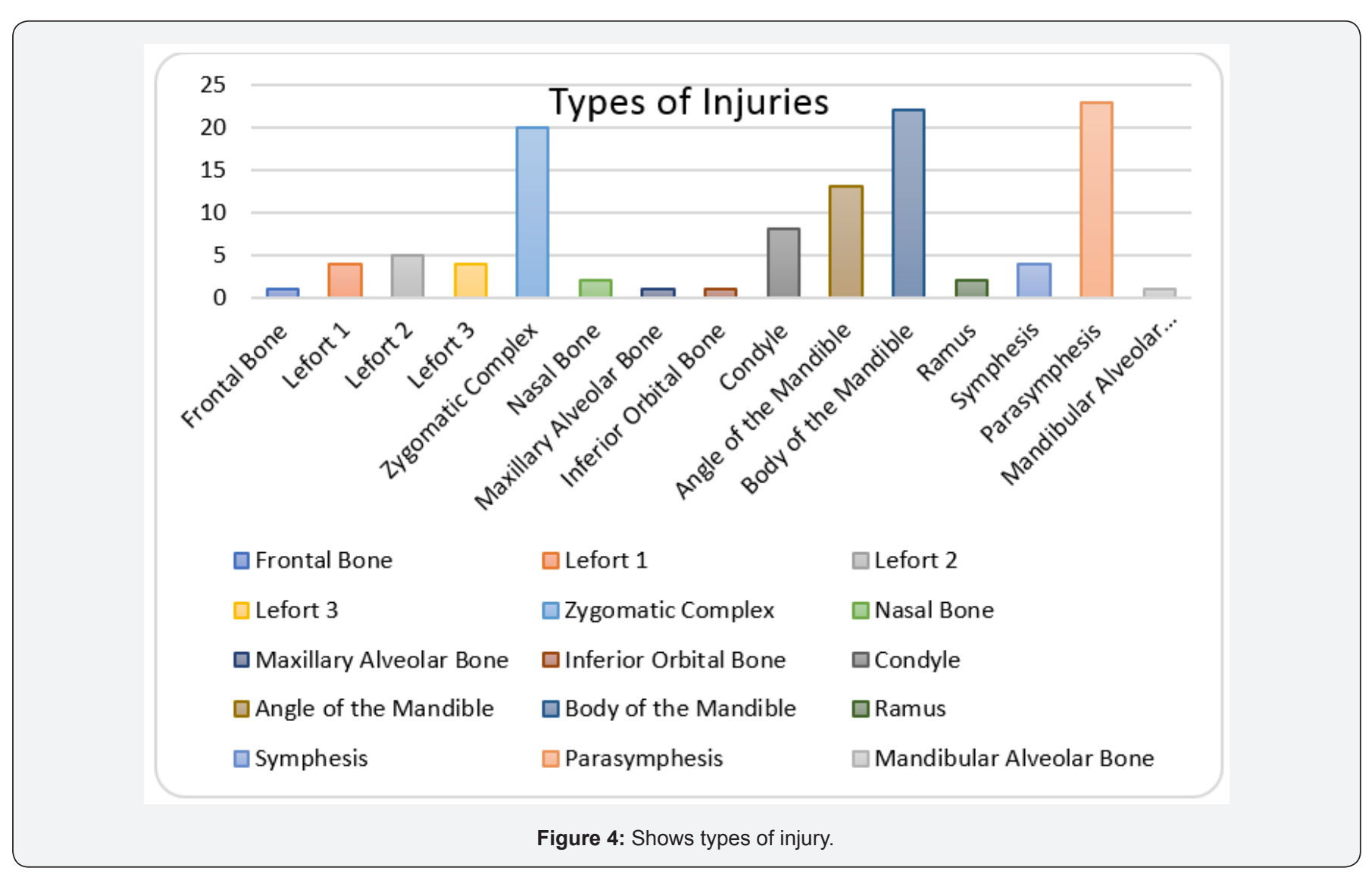

e) Regarding patients' GCS scores, 1 patient (1.3\%) had a GCS of 12,11 patients (14.7\%) had a GCS of 14,26 patients
$(34.7 \%)$ had a GCS score of 15 , while 37 patients did not have their GCS score recorded (Figure 5).

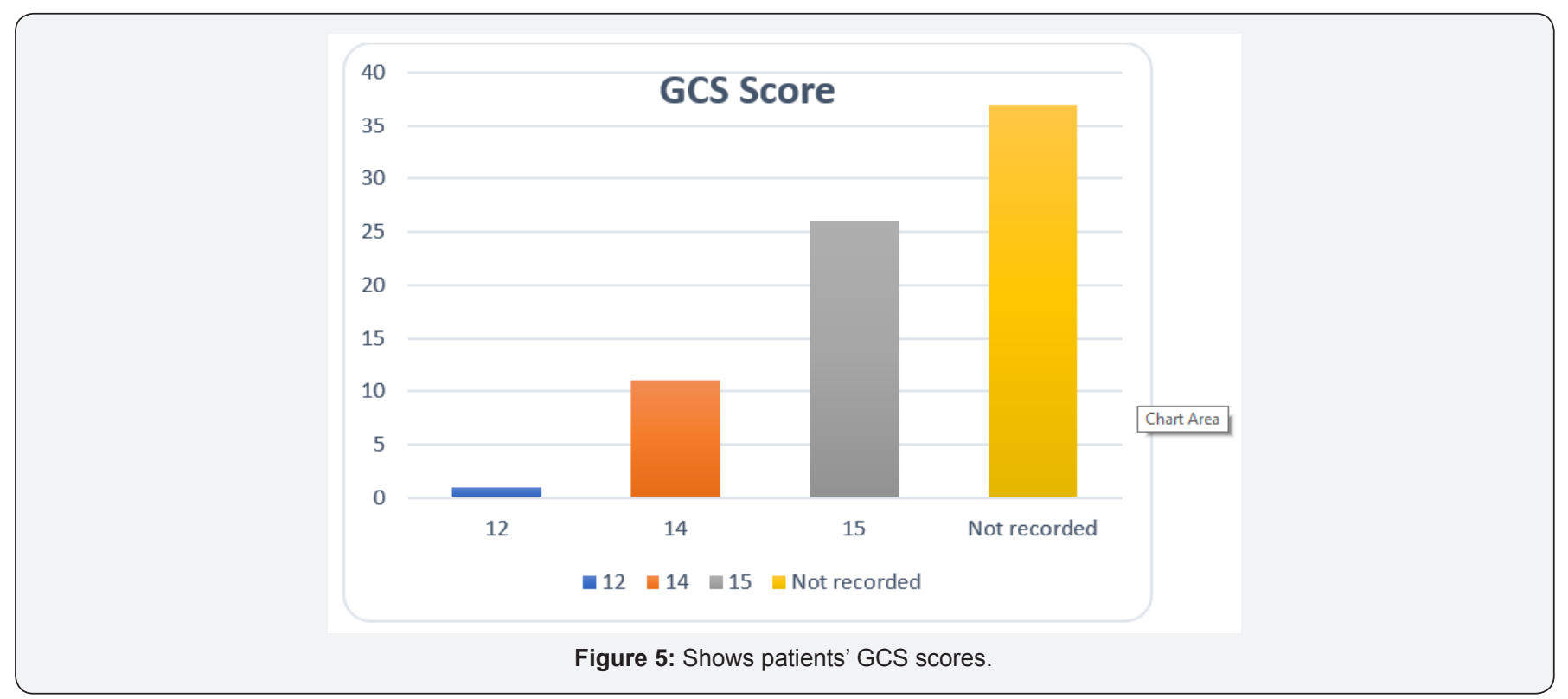


f) Among 75 patients diagnosed with maxillofacial trauma, 29 (38.7\%) experienced loss of consciousness and $46(61.3 \%)$ did not (Figure 6).

g) Regarding the duration of loss of consciousness, 13 patients (44.8\%) lost consciousness for less than 30 minutes, 11 patients (37.9\%) lost consciousness for 30 minutes -6 hours, and 5 patients (17.2\%) were unconscious for over 6 hours (Figure 7).

h) Regarding anterograde amnesia, only one of 75 patients $(1.3 \%)$ sustained anterograde amnesia following injury Figure 8.

\section{Loss of Consciousness}

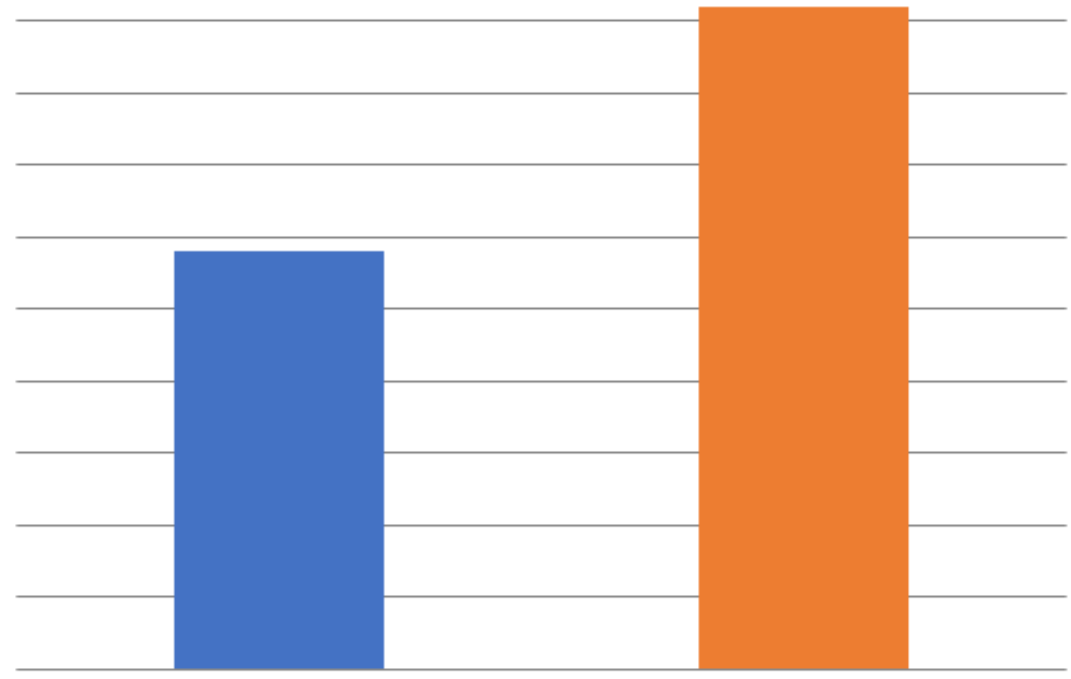

Figure 6: Shows Loss of Consciousness in Maxillofacial trauma patients.

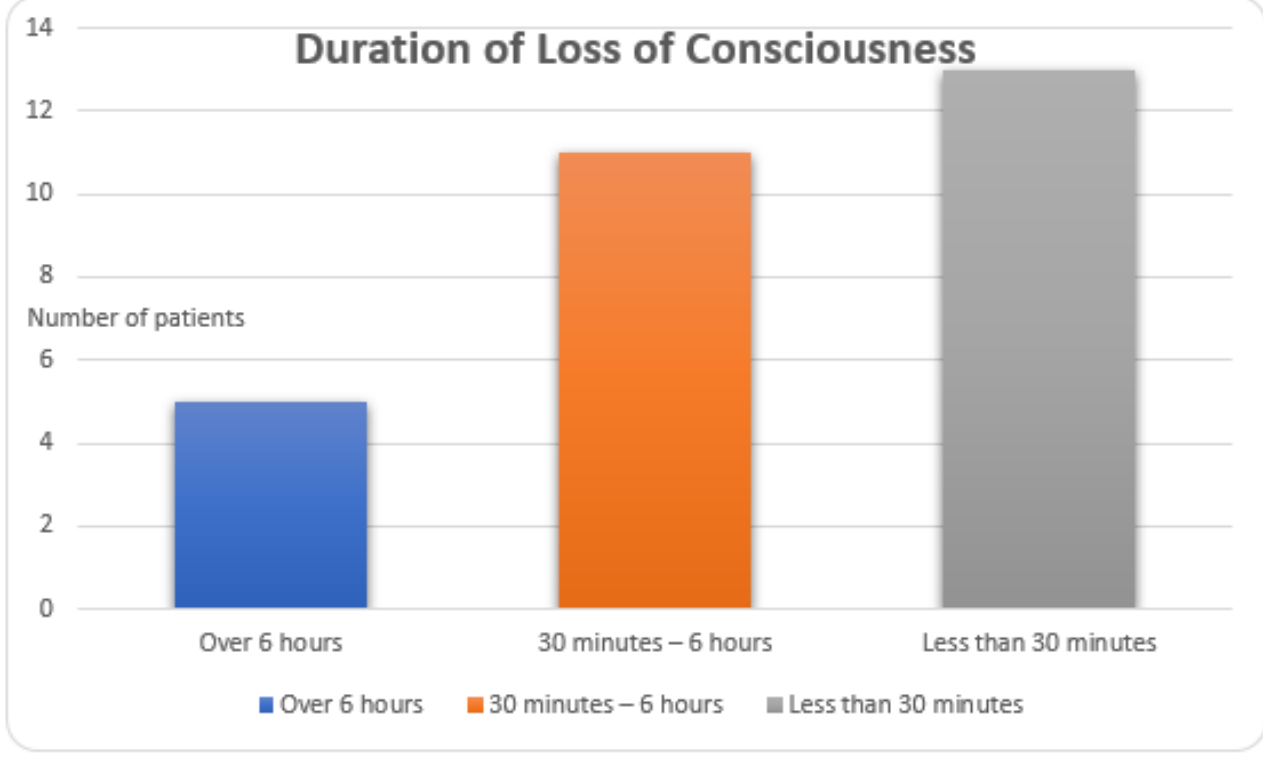

Figure 7: Shows duration of loss of consciousness. 


\section{Anterograde Amnesia}

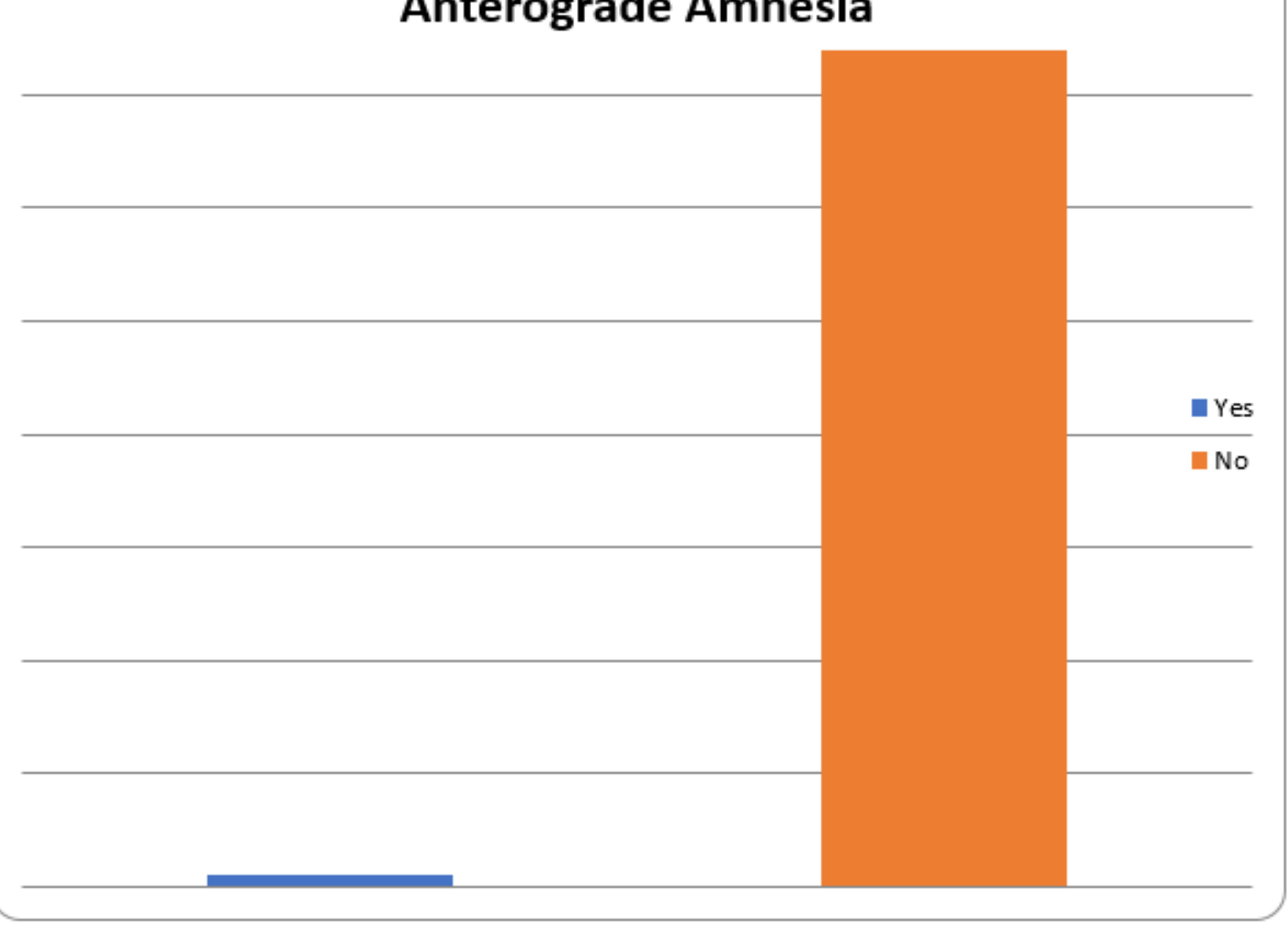

Figure 8: Shows Anterograde Amnesia.

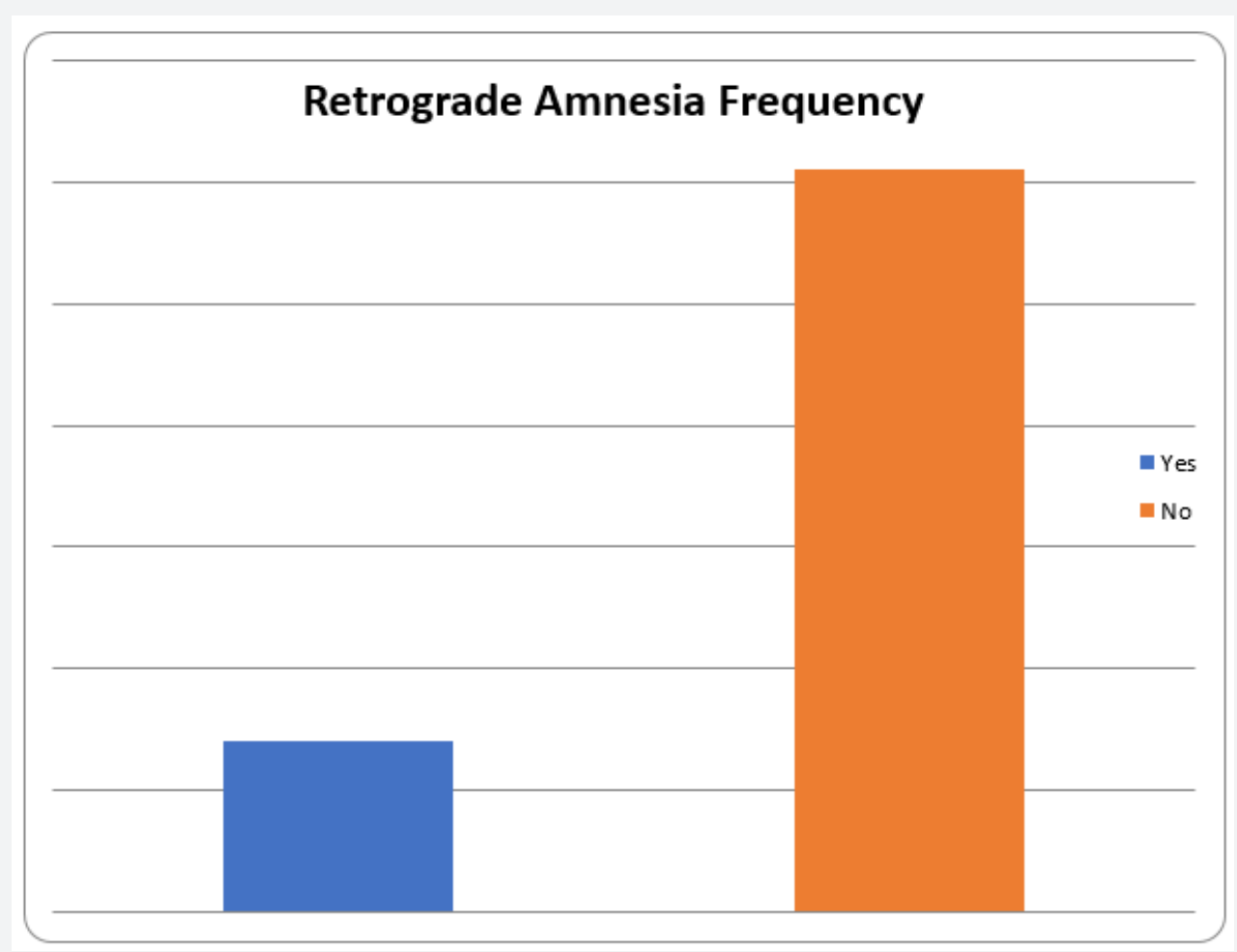

Figure 9: Shows Retrograde Amnesia. 
i) Regarding retrograde amnesia, a total of 14 patients $(18.7 \%)$ had experienced it, while $61(81.3 \%)$ did not (Figure 9).

j) Regarding the duration of retrograde amnesia, 2 patients $(14.2 \%)$ reported being amnesic for around 15 minutes, 3 patients $(21.4 \%)$ reported being amnesic for around 30 minutes, 1 patient $(7.1 \%)$ reported being amnesic for 1 hour, 2 patients (14.2\%) reported being amnesic for 2 hours, 2 patients (14.2\%) reported being amnesic for 3 hours, 2 patients $(14.2 \%)$ reported being amnesic for around 24 hours, and 2 patients (14.2\%) reported being amnesic for over 24 hours (Figure 10).

\section{Duration of Retrograde Amnesia}

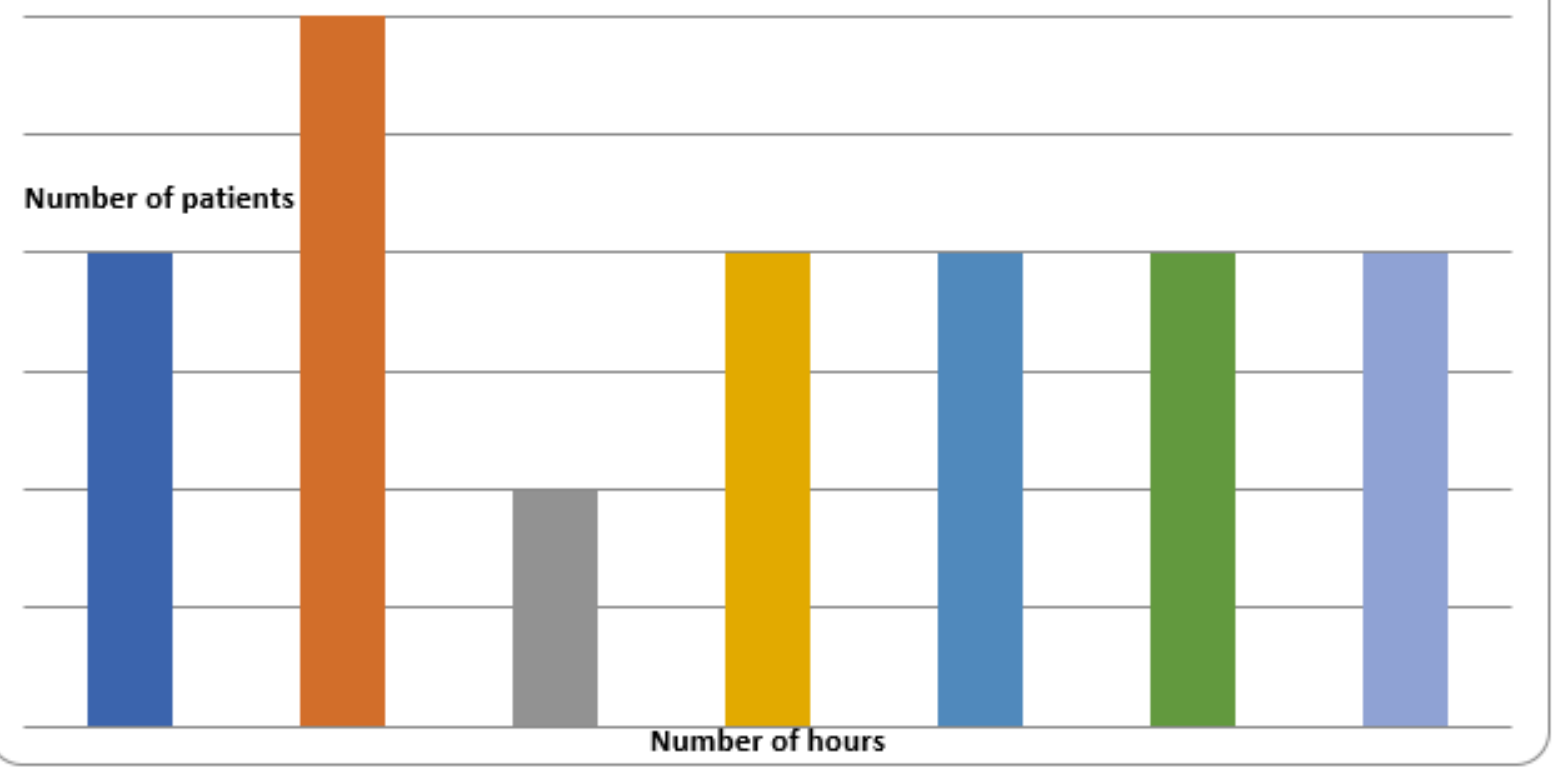

Figure 10: Shows Duration of Retrograde Amnesia.

Figure 11: Shows other symptoms of head injury. 
k) Concerning other symptoms of head injury, headache was found in 14 patients (18.7\%), followed by dizziness, which was found in 11 patients (14.7\%), followed by blurred vision, found in 6 patients (8\%) while the least experienced symptom was nausea and vomiting, which reported in only $2(2.7 \%)$ of patients. One patient reported developing anosmia, and another reported left eye visual deterioration and impaired hearing. 42 patients (56\%) did not experience any of these symptoms (Figure 11).

\section{Discussion}

In this study, $90.7 \%$ of patients with maxillofacial trauma were males and only 9.7\% were females. The ages were from 1870 and the mean age was found to be 33 years. This is similar to a study conducted by Sobin et al. [6] where $88 \%$ of patients that had met the study criteria were males, $12 \%$ were females, and the mean age was 27.5 years [6].

The causes of injury in this study were RTA's in 35 injuries (47\%), followed by assault causing 22 injuries (29\%), followed by falls causing 12 injuries (16\%), followed by sport-related injuries, causing 3 injuries (4\%) and 3 Other injuries accounting for $(4 \%)$. The injuries in the "Other" category was 1 blast injury, 1 traumatic extraction and 1 work-related injury. In contrast, the most common causes of injury in the study conducted by Sobin et al. [6] were assault (75\%), followed by sport-related injuries (13\%) and RTAs in only (6\%) of the patients [6]. These differences between the two results may be due to the difference in environmental factors, as studies have shown that the most prevalent cause of maxillofacial trauma in underdeveloped countries such as Sudan are RTAs, while assault remains the number one cause of maxillofacial trauma in developed countries such as USA, where the other study was conducted.

Concerning the types of injuries, the most common type of injury was fracture of the parasymphesis $(20.7 \%)$, followed by the body of the mandible $(19.8 \%)$ and the zygomatic complex $(18 \%)$ while the least encountered fractures were those of the upper third of the face.

Regarding patients' GCS scores, 1 patient (1.3\%) had a GCS of 12,11 patients $(14.7 \%)$ had a GCS of 14,26 patients $(34.7 \%)$ had a GCS score of 15 , while 37 patients did not have their GCS score recorded. This result may be due to the fact that the GCS scores were only recorded pre-operatively and not on prior examination of the patient. As stated by Michael J Slater [7], it is likely that the patient initially had a lower GCS score, but was oriented by the time they were assessed for the operation [7]. It was found that $38.7 \%$ of patients included in the study experienced loss of consciousness, where $44.8 \%$ of those patients were unconscious for less than 30 minutes, $37.9 \%$ lost consciousness for 30 minutes
-6 hours, and $17.2 \%$ were unconscious for over 6 hours. Jennett, B. confirmed that impairment of consciousness is indicative of diffuse brain damage, but there can also be marked local damage without either alteration in consciousness or amnesia [7].

In this study, the most common fractures associated with loss of consciousness were fractures of the body of the mandible and para symphysis, followed by fractures of the zygomatic complex.

Only $1.3 \%$ of patients experienced anterograde amnesia following injury, while $18.7 \%$ of patients experienced retrograde amnesia. The duration of retrograde amnesia in this study ranged from 15 minutes to several days, the average time was 15 hours. Studies have shown that amnesia for even a few minutes after a blow to the head is evidence of diffuse brain damage [7].

Concerning other symptoms of head injury, headache was reported in $18.7 \%$, followed by dizziness, which was found in $14.7 \%$, followed by blurred vision, found in $8 \%$, while the least experienced symptom was nausea and vomiting, which reported in only $2.7 \%$ of patients. One patient reported developing anosmia, and another reported left eye visual deterioration and impaired hearing. 56\% of patients did not experience any of these symptoms.

\section{Conclusion}

The results indicate that neurological manifestations are commonly associated with maxillofacial trauma, and that these injuries remain undiagnosed. It is necessary to investigate the presence of head injury in patients presenting with maxillofacial trauma in order to initiate proper management and to avoid further complications.

\section{References}

1. Hyder AA, Wunderlich CA, Puvanachandra P, Gururaj G, Kobusingye OC (2007) The impact of traumatic brain injuries: A global perspective. NeuroRehabilitation 22(5): 341-353.

2. Motamedi MH (2003) An Assessment of Maxillofacial Fractures: A 5-Year Study of 237 Patients J Oral Maxillofac Surg 61(1): 61-64.

3. Gassner R, Tuli T, Hachl O, Rudisch A, Ulmer H (2003) Craniomaxillofacial trauma: a 10year review of 9,543 cases with 21, 067 injuries. J Craniomaxillofac Surg 31(1): 51-61.

4. Bazarian JJ, McClung J, Shah MN, Cheng YT, Flesher W, et al. (2005) Mild traumatic brain injury in the United States. Brain Inj 19(2): 85-91.

5. Rutland-brown W, Langlois JA, Thomas KE, Xi YL (2006) Incidence of Traumatic Brain Injury in the United States. J Head Trauma Rehabil 21(6): 544-548.

6. Sobin L, Kopp R, Walsh R, Kellman RM, Harris T (2015) Incidence of Concussion in Patients with Isolated Mandible Fractures. JAMA Facial Plast Surg 18(1):15-18.

7. Slater MJ, Vecchio S (2001) The Extended Glasgow Coma Scale and Mtbi Limitations of the Glasgow Coma Scale in MTBI cases. 


\section{Your next submission with Juniper Publishers will reach you the below assets}

- Quality Editorial service

- Swift Peer Review

- Reprints availability

- E-prints Service

- Manuscript Podcast for convenient understanding

- Global attainment for your research

- Manuscript accessibility in different formats

( Pdf, E-pub, Full Text, Audio)

- Unceasing customer service

Track the below URL for one-step submission https://juniperpublishers.com/online-submission.php 